$\begin{array}{ll} & \text { Etnográfica } \\ \text { etnográfica } & \text { Revista do Centro em Rede de Investigação em }\end{array}$

Antropologia

vol. $12(1) \mid 2008$

Vol. $12(1)$

\title{
Práticas de nomeação em Portugal durante a Época Moderna: ensaio de aproximação
}

Naming practices in early modern Portugal: a preliminary approach

\section{Robert Rowland}

\section{(2) OpenEdition}

Journals

\section{Edição electrónica}

URL: https://journals.openedition.org/etnografica/1590

DOI: 10.4000/etnografica.1590

ISSN: 2182-2891

\section{Editora}

Centro em Rede de Investigação em Antropologia

\section{Edição impressa}

Data de publição: 1 maio 2008

Paginação: 17-43

ISSN: 0873-6561

\section{Refêrencia eletrónica}

Robert Rowland, «Práticas de nomeação em Portugal durante a Época Moderna: ensaio de aproximação», Etnográfica [Online], vol. 12 (1) | 2008, posto online no dia 19 junho 2012, consultado o 10 fevereiro 2022. URL: http://journals.openedition.org/etnografica/1590 ; DOl: https://doi.org/ 10.4000/etnografica.1590

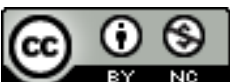

Etnográfica is licensed under a Creative Commons Attribution-NonCommercial 4.0 International License. 


\title{
Práticas de nomeação em Portugal durante a Época Moderna: ensaio de aproximação
}

\section{Robert Rowland}

\begin{abstract}
Este artigo constitui uma primeira abordagem das práticas de nomeação em Portugal na Época Moderna, procurando, com base em diferentes tipos de fontes (processos da Inquisição de Lisboa, róis de confessados e listas das companhias de ordenanças), reconstituir a emergência, a partir do século XVI, de um modelo baseado na combinação de nomes próprios (pessoais) e de nomes de família, ou apelidos, transmissíveis de geração em geração. Este processo, que é situado numa perspectiva temporal mais longa (desde a época romana), parece sugerir alguma especificidade dos modelos ibéricos no contexto europeu.

PALAVRAS-CHAVE: nome, família, linhagem, Portugal, Época Moderna.
\end{abstract}

Os nomes, segundo John Stuart Mill, têm uma função puramente denotativa. Desprovidos de significado próprio, servem apenas para distinguir as coisas (e as pessoas) umas das outras. ${ }^{1} \mathrm{Na}$ prática, contudo, a função essencialmente denotativa dos nomes - e dos nomes próprios em particular - raramente exclui a existência de funções conotativas. Longe de serem apenas meaningless marks, os nomes têm, ou adquirem através das práticas de nomeação, um significado. A função denotativa do nome serve em teoria apenas para marcar a identidade pessoal, ou a individualidade, de cada um, distinguindo-o, tal como o número do bilhete de identidade, de todas as restantes pessoas no interior de determinada população de referência. Mas precisamente na medida em que possui, ou adquire pelo uso, uma conotação ou significado próprio, um nome passa

l São "meaningless marks set upon things to distinguish them one from another" (cit. in Wilson 1998: xi). 
a poder relacionar uma pessoa com determinadas outras pessoas, ou grupos e categorias de pessoas, contribuindo assim para estabelecer a sua identidade social. ${ }^{2}$ Nestes termos, como dizia já Leite de Vasconcellos no seu estudo clássico sobre Antroponímia Portuguesa (1928: 3), o nome passa a ter simultaneamente uma dimensão social e uma dimensão moral, articulando as identidades pessoal e social dos indivíduos e contribuindo, assim, para a constituição social e moral da pessoa. ${ }^{3}$

Neste breve apontamento ${ }^{4}$ irei propor uma primeira aproximação às práticas de nomeação em Portugal durante a Época Moderna (séculos XVI-XVIII). Trata-se, no essencial, de efectuar a cartografia preliminar de um campo até agora pouco explorado, cuja investigação sistemática poderá contribuir quer para o estudo comparativo das práticas de nomeação, quer, justamente a partir dessa abordagem comparativa, para uma melhor compreensão de alguns aspectos fundamentais da história social e cultural portuguesa, em particular os que dizem respeito ao papel do parentesco nos processos de estruturação simbólica de grupos sociais.

\section{II}

Se os nomes próprios fossem, de facto, marcas sem significado, seria de esperar que a sua distribuição no interior de uma determinada população fosse aleatória e que a sua variedade fosse suficiente para eliminar, no interior de um mesmo espaço de interacção ou universo de interconhecimento, os riscos de confusão entre pessoas. E, mesmo admitindo que houvesse subpopulações espacial ou temporalmente específicas, facto esse que se poderia traduzir na existência de conjuntos regional e/ou cronologicamente específicos de nomes, a distribuição desses nomes no interior de cada uma dessas subpopulações deveria mesmo assim ser aleatória. Nestes termos, e independentemente dos nomes em si, a existência de uma distribuição regular dos nomes próprios em qualquer população, ou a persistência dessa distribuição ao longo do tempo, constitui um indício seguro do carácter socialmente significativo das práticas de nomeação.

Vejamos alguns exemplos.

Uma primeira aproximação à distribuição dos nomes próprios em Portugal durante a época moderna, e da sua evolução entre 1536 e 1820, pode ser

3 Sobre as relações entre nome e identidade, cfr. o artigo fundamental de Ian Winchester (1973).

4 Este texto corresponde a uma sondagem preliminar, destinada a constituir o ponto de partida para um estudo mais amplo, e necessariamente moroso, baseado numa amostragem representativa de registos paroquiais. Apesar das dificuldades que resultam do seu volume e dispersão, os registos paroquiais constituem a fonte mais apropriada para um estudo de conjunto das práticas de nomeação durante este período (cfr. adiante, nota 34 ). 
obtida através da análise das listas de processados da Inquisição. ${ }^{5}$ Conforme se depreende do quadro 1, havia, e manteve-se ao longo do período, uma variedade bastante considerável de nomes próprios, e em particular de nomes próprios masculinos. Entre os 16437 processados pela Inquisição de Lisboa ${ }^{6}$ (que não constituíam uma sociedade de interconhecimento nem pertenciam todos aos mesmos meios sociais e geográficos), ${ }^{7}$ cada nome próprio designava, em média, cerca de 20 indivíduos. Entre os homens houve uma tendência significativa para uma maior concentração dos nomes - cada nome designava, em

\section{Quadro I}

Nomes próprios dos processados na Inquisição de Lisboa, 1536-1820

$\begin{array}{lrrr} & \begin{array}{c}\text { Século } \\ \text { XVI }\end{array} & \begin{array}{c}\text { Século } \\ \text { XVII }\end{array} & \begin{array}{r}\text { Séculos } \\ \text { XVIII/XIX }\end{array} \\ \begin{array}{c}\text { Homens } \\ \text { Pessoas }\end{array} & 2425 & 3334 & 5191 \\ \text { Nomes } & 153 & 144 & 194 \\ \text { média } & 15,8 & 23,2 & 26,8 \\ \text { Mulheres } & & & \\ \text { Pessoas } & 1766 & 1910 & 1811 \\ \text { Nomes } & 69 & 78 & 114 \\ \text { média } & 25,6 & 24,5 & 16,5\end{array}$

Fonte: ver nota 5 .

5 Foram utilizados para esta sondagem preliminar os ficheiros informáticos elaborados, no âmbito do projecto por mim dirigido no Instituto Gulbenkian de Ciência entre 1982 e 1987, a partir do catálogo oitocentista (o "rosário") dos processos da Inquisição de Lisboa do Arquivo Nacional da Torre do Tombo. Foram excluídos os nomes estrangeiros (ex.: Hamet, Hans, Osmão, Roger, Ulrique, etc.). Os ficheiros incluem cerca de 600 processos que já não constavam do catálogo original, por os respectivos verbetes se terem extraviado. Com todas as suas limitações, estes ficheiros permitem uma primeira abordagem de conjunto das práticas de nomeação em Portugal entre 1536 e 1820. Essas limitações dizem respeito quer aos eventuais erros ou lacunas, quer à representatividade dos processados. Em relação a este último aspecto, contudo, pode argumentar-se que os cristãos-novos, alvo principal da Inquisição, não constituíam a partir de meados do século XVI uma subpopulação claramente demarcada com características culturais próprias (cfr. Rowland 1999). 6 Nem todos os documentos a que se refere o catálogo são processos completos, havendo muitos, sobretudo nas décadas finais, que correspondem a papéis avulsos ou a processos iniciados mas não concluídos. Há ainda alguns casos, não detectáveis sem uma consulta dos originais, de indivíduos que foram objecto de mais do que um processo.

7 Em alguns períodos e contextos sociais e geográficos (p. ex. os mercadores cristãos-novos de Lisboa em determinado período), os indivíduos processados pela Inquisição poderiam de facto constituir uma sociedade de interconhecimento. Mas o termo não pode, obviamente, aplicar-se ao conjunto dos processados ao longo de todo o período, ou mesmo em cada um dos três séculos considerados. 
média, 16 pessoas no século XVI, 23 no século XVII, e 27 nos séculos XVIII e XIX -, enquanto que entre as mulheres a tendência foi inversa, tendo o número médio de pessoas designadas por cada nome próprio diminuído, no mesmo intervalo, de 26 para 25 e, depois, 17.

Em contextos localizados, sobretudo em se tratando de sociedades de interconhecimento, poder-se-ia talvez esperar que o número médio de pessoas designado por cada nome fosse mais baixo e que, por conseguinte, o seu carácter discriminatório, ou a sua capacidade de identificação, fosse superior. ${ }^{8}$ E, com efeito, assim parece ter sido, embora a diferença seja relativamente pequena. $\mathrm{Na}$ freguesia de Moncarapacho, no Algarve, onde residiam em meados do século XVI 1710 pessoas com mais de $7-8$ anos, ${ }^{9}$ cada nome próprio masculino designava em média 14 pessoas e cada nome feminino 18 (quadro 2). E em 1830, na freguesia de Carreço (Viana do Castelo), segundo o respectivo Livro de Registo da Companhia de Ordenanças (cfr. Feijó 1987), havia 34 nomes masculinos, cada um dos quais designava em média 17 de entre os 570 homens recenseados (quadro 3 ).

Mas apesar de constituírem um indicador estatístico da capacidade discriminatória média dos nomes próprios em cada período ou contexto, estes valores dizem muito pouco acerca da utilização efectiva dos nomes como meio de identificação. Esta depende também, e sobretudo, da sua distribuição, que em cada uma das sub-populações aqui analisadas está longe de ser aleatória.

Entre os processados da Inquisição de Lisboa, com efeito, verifica-se uma notável concentração de nomes próprios, com os cinco nomes mais frequentes

Quadro 2

Nomes próprios dos habitantes da freguesia de Moncarapacho (Algarve), 1545

$\begin{array}{lcc} & \text { Homens } & \text { Mulheres } \\ \text { Pessoas } & 876 & 834 \\ \text { Nomes } & 63 & 47 \\ \text { média } & 13,9 & 17,7\end{array}$

Quadro 3

Nomes próprios masculinos dos habitantes da freguesia de Carreço (Viana do Castelo), c. 1830

$\begin{array}{lr}\text { Pessoas } & 570 \\ \text { Nomes } & 34 \\ \text { média } & 16,7\end{array}$

Fonte: ver nota 9.

8 Abordarei adiante o papel dos sobrenomes (patronímicos, apelidos e alcunhas: cfr. nota 31) na identificação dos indivíduos.

9 A fonte aqui utilizada é o Rol de Confessados de Moncarapacho para o ano de 1545, conservado, juntamente com outros róis da mesma década, em ANTT, Livro de Registos Paroquiais, Loulé, Moncarapacho, Mistos I, fls. 94-138. Esta fonte riquíssima, aparentemente única para o século XVI, continua à espera de uma análise adequada. 
a designarem, em cada século, entre $40 \%$ e $60 \%$ do total de homens e mulheres. Em relação aos homens há uma tendência nítida, entre os séculos XVI e XVIII/XIX, para uma crescente concentração dos nomes, que passa de $40 \%$ a $58 \%$. Entre as mulheres verifica-se uma oscilação à volta do marco dos 50\%. Há, por outro lado, um número muito significativo de nomes pouco frequentes, com uma elevada capacidade discriminatória, cujos portadores representam, contudo, uma proporção ínfima do total. No século XVI, por exemplo, há 66 nomes masculinos e 17 nomes femininos que têm apenas um portador. Representam 43\% e 25\% dos nomes, respectivamente, mas designam apenas $2,7 \%$ e $1 \%$ das pessoas. Embora os números exactos sejam ligeiramente diferentes, o fenómeno repete-se ao longo dos séculos XVII e XVIII/XIX (quadro 4).

Em populações mais pequenas, que correspondem a sociedades de interconhecimento, os nomes serviriam em princípio para identificar as pessoas,

Quadro 4

Distribuição dos nomes próprios dos processados da Inquisição de Lisboa, 1536-1820

a) Pessoas com os cinco nomes mais frequentes

$\begin{array}{ccc}\text { Século } & \text { Século } & \text { Séculos } \\ \text { XVI } & \text { XVII } & \text { XVIII/XIX }\end{array}$

Homens

$\begin{array}{lrrr}\text { Pessoas } & 971 & 1948 & 3011 \\ \% \text { do total } & 40,0 & 44,9 & 58,0\end{array}$

Mulheres

$\begin{array}{lrrr}\text { Pessoas } & 842 & 1042 & 852 \\ \% \text { do total } & 47,7 & 54,6 & 45,3\end{array}$

b) Pessoas com nomes únicos

$\begin{array}{ccc}\text { Século } & \text { Século } & \text { Séculos } \\ \text { XVI } & \text { XVII } & \text { XVIII/XIX }\end{array}$

Homens

$\begin{array}{lrrr}\text { Pessoas } & 66 & 42 & 58 \\ \% \text { dos nomes } & 43,1 & 29,3 & 29,9 \\ \% \text { das pessoas } & 2,7 & 1,3 & 1,1\end{array}$

Mulheres

$\begin{array}{lrrr}\text { Pessoas } & 17 & 26 & 40 \\ \text { \% dos nomes } & 24,6 & 33,3 & 35,1 \\ \text { \% das pessoas } & 1,0 & 1,4 & 2,1\end{array}$


distinguindo-as dos demais membros da mesma comunidade. É, por isso, extremamente significativo que o fenómeno se repita, com valores em tudo comparáveis ou até mais extremos, nas duas freguesias que são aqui objecto de análise. Em Moncarapacho, em meados do século XVI, os cinco nomes mais frequentes correspondiam a $44 \%$ da população masculina e a $55 \%$ da feminina. Mas, em contrapartida, havia com um único portador 20 nomes masculinos e 11 femininos, respectivamente $32 \%$ e $23 \%$ do total de nomes, a que correspondiam $2 \%$ e $1 \%$ da população (quadro 5). Em Carreço, na primeira metade do século XIX, do mesmo modo, os cinco nomes mais frequentes correspondiam a $79 \%$ da população, havendo ao mesmo tempo 13 nomes únicos, correspondentes a $38 \%$ do total, que abrangiam pouco mais de $2 \%$ da população (quadro 6 ).

\section{Quadro 5}

Distribuição dos nomes próprios na freguesia de Moncarapacho (Algarve), 1545

a) Pessoas com os cinco nomes mais frequentes

$\begin{array}{lcc} & \text { Homens } & \text { Mulheres } \\ \text { Pessoas } & 384 & 461 \\ \% \text { do total } & 43,8 & 55,3\end{array}$

b) Pessoas com nomes únicos

$\begin{array}{lcc} & \text { Homens } & \text { Mulheres } \\ \text { Pessoas } & 20 & 11 \\ \text { \% dos nomes } & 31,7 & 23,4 \\ \text { \% das pessoas } & 2,3 & 1,3\end{array}$

Fonte: ver nota 9.

Quadro 6

Distribuição dos nomes próprios masculinos na freguesia de Carreço (Viana do Castelo), c. 1830

a) Pessoas com os cinco nomes mais frequentes

$\begin{array}{lr}\text { Pessoas } & 451 \\ \% \text { do total } & 79,1\end{array}$

b) Pessoas com nomes únicos

$\begin{array}{lr}\text { Pessoas } & 13 \\ \% \text { dos nomes } & 38,2 \\ \% \text { das pessoas } & 2,3\end{array}$


Verificamos, assim, que, ao longo da Época Moderna, apesar de se poder imaginar que a escolha do nome próprio seria, tal como nas sociedades contemporâneas, um acto privado, de âmbito familiar quando não individual, a distribuição dos nomes próprios em três subpopulações distintas - o conjunto dos processados pela Inquisição de Lisboa (1536-1820), os habitantes da freguesia de Moncarapacho, no Algarve, em 1545, e a população masculina da freguesia de Carreço, no Minho, em 1830 - apresentava sensivelmente as mesmas características: uma significativa concentração de nomes próprios, com entre $40 \%$ e $79 \%$ de cada população a partilhar os cinco nomes mais frequentes; e, inversamente, uma proporção não menos significativa dos nomes próprios (23\% a 43\%) que em cada população designava um indivíduo apenas. Mesmo que as escolhas tenham sido individuais ou familiares, esta distribuição, que se reproduz ao longo de três séculos em contextos muito diferenciados entre si, sublinha o carácter social dos critérios de escolha e, por conseguinte, das práticas de nomeação. ${ }^{10}$

III

Uma conclusão análoga, embora de carácter talvez mais cultural que social, pode ser retirada de uma análise da frequência com que, nestas três subpopulações, determinados nomes foram sendo escolhidos.

Em relação aos processados pela Inquisição de Lisboa - o único, de entre os exemplos aqui focados, a permitir uma análise diacrónica - os quadros 7 e 8 mostram que, com poucas excepções, os nomes masculinos e femininos escolhidos com maior frequência no século XVI continuavam a sê-lo nos dois séculos seguintes. Entre os nomes masculinos, o de Jorge desaparece da lista dos dez nomes mais frequentes depois do século XVI, os de Gaspar e Simão depois do século XVII, sendo substituídos, respectivamente, por Domingos e por Joaquim e José. Entre os nomes femininos, desaparecem depois do século XVI os de Filipa e Guiomar, depois do século XVII os de Branca, Violante e Inês. Os nomes que os substituíram foram, no século XVII, o de Joana e, nos séculos XVIII/XIX, os de Mariana, Josefa e Antónia. A grande maioria dos nomes próprios, sobretudo dos masculinos, manteve a sua popularidade - e, na maioria dos casos, a sua posição relativa - ao longo deste período de quase três séculos. Em relação aos homens, as alterações mais significativas foram a subida na posição relativa de Manuel ( $4 .^{\circ}$ no século XVII, $1 .^{\circ}$ a partir de então), a descida de João $\left(1 .^{\circ}\right.$ no século XVI, depois $3 .^{\circ}$ e $\left.4 .{ }^{\circ}\right)$, e a repentina popularidade

10 Esta distribuição não era excepcional na Europa da Época Moderna. Em França, que é de longe o caso mais estudado, verifica-se a mesma concentração de nomes muito comuns associada à existência de nomes muito infrequentes. Cfr. Burguière (1980) e, para um esboço de análise comparada, Wilson (1998: 185-241). 
Quadro 7

Nomes masculinos mais frequentes dos processados da Inquisição de Lisboa, 1536-1820

\begin{tabular}{lclrlrr}
\multicolumn{1}{c}{$\begin{array}{c}\text { Século } \\
\text { XVI }\end{array}$} & \multicolumn{2}{c}{$\begin{array}{c}c \\
\text { Xéculo } \\
\text { XVII }\end{array}$} & \multicolumn{2}{c}{ Séculos } \\
Nome & $\%$ & Nome & Nome & $\%$ \\
João & 11,0 & Manuel & 14,1 & Manuel & 15,4 \\
António & 9,8 & António & 10,8 & José & 14,0 \\
Pedro & 7,5 & João & 10,7 & António & 13,5 \\
Manuel & 6,1 & Francisco & 4,8 & João & 11,0 \\
Diogo & 5,7 & Pedro & 4,6 & Francisco & 4,1 \\
Francisco & 4,3 & Diogo & 4,5 & Luís & 3,3 \\
Simão & 3,3 & Luís & 3,5 & Joaquim & 2,5 \\
Gaspar & 3,0 & Simão & 3,0 & Diogo & 2,3 \\
Luís & 2,9 & Domingos & 2,8 & Domingos & 2,3 \\
Jorge & 2,6 & Gaspar & 2,3 & Pedro & 2,2
\end{tabular}

Fonte: ver nota 5 .

Quadro 8

Nomes femininos mais frequentes dos processados da Inquisição de Lisboa, 1536-1820

\section{Século}

XVI

$\begin{array}{lrl}\text { Nome } & \% & \text { Nome } \\ \text { Isabel } & 13,3 & \text { Maria } \\ \text { Beatriz } & 9,6 & \text { Isabel } \\ \text { Maria } & 9,3 & \text { Beatriz } \\ \text { Leonor } & 8,6 & \text { Catarina } \\ \text { Catarina } & 7,0 & \text { Ana } \\ \text { Branca } & 6,9 & \text { Leonor } \\ \text { Ana } & 5,0 & \text { Joana } \\ \text { Inês } & 3,7 & \text { Branca } \\ \text { Filipa } & 3,2 & \text { Violante } \\ \text { Violante } & 3,0 & \text { Inês } \\ \text { Guiomar } & 3,0 & \end{array}$

Século

XVII
Séculos

XVIII/XIX
5,4

4,0

3,5

I,O

, 1

2,3

2,2 
de José, que no século XVI tinha sido escolhido em apenas um caso $(0,04 \%)$, no século XVII 62 vezes (1,9\%), e que no último período ocupava o segundo lugar, com 729 (14,0\%). Em relação às mulheres, há que assinalar apenas a crescente popularidade do nome Maria que, no século XVI, ocupava o terceiro lugar (9,3\%), passando em seguida para o primeiro, com 19,9\% e 20,2\%.

Em relação aos outros dois exemplos, como se disse, não é possível efectuar uma análise diacrónica. Mas uma comparação dos quadros 9 e 10 com os dois anteriores permite entrever, independentemente de eventuais evoluções ao longo do tempo, como, por um lado, podia haver em pequenas populações um conjunto regional ou localmente específico de nomes, sem que, por outro, esses conjuntos deixassem de se conformar com o modelo mais amplo nacional. Seria o caso, talvez, de considerar estas três subpopulações como exemplos, respectivamente, de uma great e de duas little traditions.

Estamos aqui, evidentemente, perante um modelo cultural cujas variações no tempo e no espaço não são suficientes para comprometer a sua coerência intrínseca. Infelizmente, as fontes aqui em estudo não permitem, salvo num aspecto, uma análise do seu conteúdo ou dos factores subjacentes às variações detectadas. Esse aspecto diz respeito à eventual associação entre o estatuto social e a frequência com que determinados nomes eram escolhidos.

As listas de processados da Inquisição só muito excepcionalmente registam alguma informação - geralmente sob a forma de alcunhas - a respeito da ocupação dos acusados. O carácter esporádico desta informação, e o facto de

Quadro9

Nomes mais frequentes em Moncarapacho, 1545

Homens

\begin{tabular}{lrlr}
\multicolumn{1}{c}{ Homens } & \multicolumn{2}{c}{ Mulheres } \\
Nome & $\%$ & Nome & Catarina \\
João & 19,6 & Maria & 16,8 \\
Domingos & 8,4 & Isabel & 14,6 \\
António & 5,7 & Inês & 9,6 \\
Pedro & 5,1 & Beatriz & 6,6 \\
Francisco & 4,9 & Bárbara & 6,0 \\
Diogo & 4,6 & Constança & 5,5 \\
Manuel & 4,6 & Leonor & 4,8 \\
Martim & 4,3 & Margarida & 4,1 \\
Gaspar & 4,1 & Joana & 2,8 \\
Afonso & 3,3 &
\end{tabular}

Fonte: ver nota 9.
Quadro 10

Nomes masculinos mais frequentes. Carreço, c. 1830

$\begin{array}{lr}\text { Nome } & \% \\ \text { Manuel } & 19,6 \\ \text { Domingos } & 8,4 \\ \text { António } & 5,7 \\ \text { José } & 5,1 \\ \text { Francisco } & 4,9 \\ \text { João } & 4,6 \\ \text { Silvestre } & 4,6 \\ \text { Tomé } & 4,3 \\ \text { Agostinho } & 4,1 \\ \text { Joaquim } & 3,3\end{array}$

Fonte: Feijó (1987). 
dizer respeito quase sempre a artesãos e trabalhadores, torna-a inútil para a análise proposta. Mas uma indicação aceitável, apesar de grosseira, de estatuto social, pelo menos em relação aos homens, pode ser fornecida pela utilização de determinados títulos (Dom, Doutor, Licenciado, Mestre, Licenciado, Frei, Padre, Vigário). Durante o século XVI, os nomes de António e Luís estavam associados a um estatuto social mais elevado (17,1\% e 5,7\% entre os acusados cujo título é referido, contra 9,4\% e 2,7\%, respectivamente, entre os que não tinham título). No século XVII, apenas o nome de António manteve esta diferença (14,9\% contra 10,4\%) que, nos séculos XVIII e XIX, se tornaria muito mais esbatida (14,1\% contra 13,3\%). Em contrapartida, no século XVI o nome de Manuel era mais frequente entre os acusados sem título $(6,3 \%$ contra $2,4 \%)$, mas esta diferença reduziu-se no século seguinte (14,3 contra 12,3) e desapareceu no último período. O nome de José que, como vimos, só adquiriu popularidade a partir do século XVIII, era nesse período mais frequente entre os acusados sem título ( $14,8 \%$ contra 10,8\%).

Apesar das diferenças serem relativamente pouco marcadas, será também de assinalar que os nomes cuja popularidade relativa estava a aumentar (Manuel entre o século XVI e XVII, José entre o século XVII e XVIII: cfr. quadro 7) eram mais frequentes entre os acusados sem título, o que poderá constituir uma indicação de que a crescente popularidade desses nomes próprios não estava associada a qualquer efeito de demonstração relacionado com o estatuto social.

No caso de Moncarapacho em 1545, é possível comparar a frequência dos nomes próprios dos 249 membros livres dos 73 fogos com escravos e dos 1324 membros dos fogos sem escravos. Apesar de haver poucas diferenças em relação à maioria dos nomes, os de Diogo, Francisco e Constança são bastante mais frequentes entre os proprietários de escravos do que entre os demais $(7,1 \%$ contra $4,2 \%, 7,1 \%$ contra $4,0 \%$ e $9,8 \%$ contra $5,2 \%$, respectivamente), sendo que os nomes de Leonor (5,6\% contra 1,6\%) e, em medida bastante inferior, o de Maria (15,1\% contra 13,1\%) eram mais frequentes nos estratos menos ricos.

Sempre no caso de Moncarapacho, torna-se possível verificar, ainda, até que ponto havia práticas de nomeação específicas em relação aos escravos ( $8 \%$ da população). Como se pode ver no quadro 12, o nome mais frequente entre os escravos - António (15,9\%) - era-o muito menos (4,7\%) entre a população livre. Os nomes Francisco e Pedro também eram mais frequentes entre os escravos, sendo João, pelo contrário, bastante mais frequente entre os homens livres $(20,0 \%$ contra 15,6\%). Entre as mulheres, particularmente associados com o estado servil os nomes de Bárbara (18,2\% contra 5,1\%) e Joana (10,9\% contra 2,2\%), embora houvesse outros (Simoa, Violante) que também eram ligeiramente mais frequentes entre as escravas, e vários - Domingas, Firma, Ginebra, Graça, Helena, Luzia, Madalena, Marta e Vera - que só se encontravam entre as escravas. Apesar de estes nomes só ocorrerem uma única vez nesta população, o facto de haver catorze vezes mais mulheres livres que escravas 
torna significativa a sua total ausência entre aquelas. ${ }^{11}$ Havia também alguns nomes relativamente frequentes entre as mulheres livres - Beatriz $(7,2 \%)$ e Constança $(5,9 \%)$ - que não se encontram entre as escravas, embora neste caso a desproporção entre as populações livre e servil torne a diferença menos significativa.

Confrontando os quadros 1 l e 12, verificamos que Francisco, um dos nomes associados aos fogos mais ricos (de proprietários de escravos), é de facto bastante mais frequente entre os escravos do que entre a população livre no seu conjunto, enquanto que os outros dois nomes associados a um estatuto social mais elevado ou eram menos frequentes (Diogo) ou inexistentes (Constança) entre a população escrava. Inversamente, o nome de Leonor, mais frequente entre os fogos sem escravos $(5,6 \%$ contra $1,6 \%)$, também o era entre as escravas $(5,0 \%$ contra $1,8 \%$ na população livre).

Qualquer conclusão mais firme acerca das práticas de nomeação teria de basear-se em fontes - como os registos de baptismo de escravos - que contivessem informação contextual acerca de casos individuais. Mas poder-se-á talvez concluir, com base na análise deste rol de confessados, que a hipótese de os nomes dados aos escravos tinham origens diversas. Por um lado, darse-ia às vezes ao escravo o nome do seu proprietário, sobretudo quando este era também seu padrinho de baptismo. Explicar-se-ia, assim, a atribuição de nomes associados à camada mais rica da população local, como Francisco e, eventualmente, também Joana. Por outro lado, também se davam a escravos nomes muito infrequentes, talvez como forma de os individualizar. ${ }^{12}$ Os escravos poderiam, finalmente, receber nomes de santos, como António ou Bárbara. Embora possa haver a tentação de se atribuir a elevada frequência deste último nome entre as escravas ao seu sentido literal e às conotações com uma origem exótica, parece mais provável que se trate apenas de um reflexo da devoção popular a santa Bárbara nesta zona do Algarve.

Estes números - ou melhor, estas associações - servem, com todas as limitações que derivam da natureza das fontes utilizadas, para ilustrar o modo como os nomes próprios não denotam apenas, como também conotam, funcionando na prática, e independentemente dos propósitos subjacentes à escolha de determinado nome, como marcadores de estatuto social. ${ }^{13}$ Mas as

11 Estes nomes eram igualmente infrequentes entre as 1766 processadas pela Inquisição de Lisboa no século XVI. Com a excepção de Graça (2,7\%), todos os outros tinham frequências entre 0 (Firma, Vera) e $0,6 \%$ (Helena e Madalena).

12 Tanto mais que os escravos, ao contrário da população livre, não possuíam nomes de família que contribuíssem para os distinguir. Cfr. adiante.

13 As fontes aqui utilizadas não permitem mais do que esta primeira e muito grosseira aproximação. A análise de uma amostragem representativa de processos da Inquisição permitiria, por exemplo, verificar se havia nomes próprios associados a determinadas minorias. Como exemplo das conclusões a que se poderia chegar, poderá referir-se que uma sondagem preliminar [continua] 
Quadro 11

Moncarapacho, 1545.

Fogos com escravos e sem escravos: frequência dos nomes próprios

Fogos com escravos Fogos sem escravos

$\begin{array}{lcc}\text { Homens } & \%(N=127) & \%(N=667) \\ \text { João } & 21,3 & 19,8 \\ \text { Diogo } & 7,1 & 4,2 \\ \text { Francisco } & 7,1 & 4,0 \\ \text { Pedro } & 6,3 & 4,5 \\ \text { António } & 5,5 & 4,5 \\ \text { Mulheres } & \%(N=122) & \%(N=657) \\ \text { Catarina } & 15,6 & 17,5 \\ \text { Maria } & 13,1 & 15,1 \\ \text { Constança } & 9,8 & 5,2 \\ \text { Leonor } & 1,6 & 5,6\end{array}$

Fonte: ver nota 9.

Quadro 12

Moncarapacho, 1545. População livre e escrava: frequência dos nomes próprios

\section{Homens}

Nome

$\begin{array}{lr}\text { Escravos } & \text { Livres } \\ \%(N=82) & \%(N=794)\end{array}$

António

João

Francisco

Pedro

Domingos

Manuel

Gaspar

Diogo

Jorge

Simão

$$
15,9
$$

15,6

8,5

8,5

7,3

6,1

6,1

3, 7

3, 7

3, 7
4,7

20,0

4,5

4,8

8,6

4,4

3,9

4,7

I,O

1,9

\section{Mulheres}

Escravas Livres

$\%(N=55) \quad \%(N=779)$

Bárbara

18,2

5,1

Maria

12,7

14,8

Catarina

10,9

17,2

Joana

10,9

2,2

Isabel

9,1

9,6

Simoa

3, 6

1,6

Violante

3, 6

I,6

Inês

1,8

8,0

Leonor

1,8

5,0

Ana

I,8

1,6

Guiomar

I,8

1,6 
associações detectadas são quase todas bastante ténues. Salvo, talvez, no caso de algumas das escravas de Moncarapacho, ninguém poderia com um elevado grau de probabilidade atribuir um estatuto social aos indivíduos em causa apenas com base no seu nome próprio. Nestes termos, e apesar de alguns deles possuírem conotações evidentes, os nomes próprios não bastam, no caso das populações aqui em foco, para estabelecer uma relação inequívoca entre uma pessoa e outras pessoas, marcando-as como pertencentes a determinada categoria social. Do mesmo modo, salvo no caso das poucas pessoas com nomes muito infrequentes, o nome próprio não bastava para identificar uma pessoa, distinguindo-a das restantes que integravam o seu espaço de interacção e interconhecimento.

\section{IV}

Mas a identificação das pessoas nunca foi, no contexto europeu durante a Época Moderna, função exclusiva dos nomes próprios. Desde a Idade Média, com efeito, e retomando o que tinha sido a tradição romana, as pessoas começaram cada vez mais a ser identificadas pela combinação de dois tipos de nomes: os nomes próprios, conferidos na altura do baptismo, e um ou mais sobrenomes. ${ }^{14}$

$\mathrm{Na}$ tradição romana ${ }^{15}$ os indivíduos tinham sido identificados pelos tria nomina: o praenomen, ou nome próprio, que era atribuído pouco depois da nascença; o nomen, que indicava qual o clã, ou gens, a que pertenciam; e o cognomen, que tanto podia ser uma alcunha pessoal como um nome de família, hereditário, que neste caso indicava a pertença a um ramo específico da gens. Inicialmente, segundo os autores romanos, as pessoas teriam tido apenas o nome próprio. Depois, teriam passado a usar dois nomes, e, mais tarde, à volta do segundo século a.C. (provavelmente em consequência da crescente dimensão e complexidade da sociedade romana), o sistema dos três nomes ter-se-ia tornado universal. O número total de praenomina era relativamente restrito: no primeiro século d.C. falava-se em trinta, dos quais apenas quinze em uso geral.

[continuação] efectuada em tempos sobre um conjunto (não representativo) de cerca de mil processos da Inquisição de Lisboa do século XVI detectou associações estatisticamente significativas entre a acusação de judaismo (e, por conseguinte, a condição de cristão-novo) e vários nomes próprios, entre os quais Ana, Branca e Manuel. Os nomes de Maria e António, pelo contrário, estavam associados - nesse conjunto de processos - à acusação de maometismo, e o nome Pedro com a condição de escravo. Cfr., no entanto, Vasconcellos, que afirma - sem qualquer análise estatística da frequência de cada nome - "[...] no que respeita ao nome não existe [...] diferença entre os Cristãos-Novos e Cristãos-Velhos.” (1928: 399). 14 No contexto europeu, é costume distinguir-se apenas entre nomes próprios, ou de baptismo, e nomes de família. No contexto português, como se verá, o processo de formação dos nomes de família, ou apelidos, foi mais complexo, pelo que usarei o termo genérico sobrenome para os diferentes tipos de nomes - patronímicos, apelidos e alcunhas - que eram acrescentados ao nome próprio. Cfr. adiante, nota 31 .

15 Para o que se segue ver a excelente síntese de Wilson (1998: 1-61). 
De entre estes, havia uns muito mais comuns que os outros. Nas inscrições do período republicano há 17 praenomina que ocorrem mais de dez vezes; de entre estes, seis ou sete aparecem mais de cem vezes e dois - Lucius e Gaius - mais de quinhentas vezes. Face a esta concentração de nomes próprios, e ao restrito número de nomina, a função de identificação passou a ser cada vez mais desempenhada por um ou mais cognomina que, pelo seu encadeamento, traduziam as sucessivas subdivisões de uma gens original. ${ }^{16}$ A partir do segundo século d. C., no entanto, o praenomen começou a cair em desuso, salvo na aristocracia, onde funcionava essencialmente como marcador de estatuto social. Apesar de fazerem parte de um conjunto familiar hereditário, combinações diferentes de cognomina passaram a ser atribuídas, servindo para distinguir entre si diferentes membros de uma mesma família.

Durante os últimos séculos do Império, houve duas tendências opostas. Ao mesmo tempo que os membros da aristocracia tradicional utilizavam um longo encadeamento de cognomina para evidenciar a sua ascendência, a grande maioria da população passou progressivamente a adoptar um sistema cada vez mais diversificado de nome próprio único. Após a queda do Império este sistema manteve-se, com a paulatina substituição de nomes latinos por nomes germânicos, muitos dos quais eram nomes compostos, ou ditemáticos, formados pela junção de dois elementos autónomos. Em Ravena, no século VI, por exemplo, havia cerca de um nome por pessoa. A pertença familiar era assinalada, não por nomes adicionais, mas por características dos próprios nomes: a aliteração, ou repetição de letras comuns aos nomes dos membros de um mesmo grupo de parentesco; a repetição, no interior desse grupo de parentesco, dos mesmos elementos na composição de nomes compostos; ou, mais tarde, a repetição, no interior do grupo, de nomes inteiros, de uma geração a outra ou em gerações alternadas. Em todas estas soluções, será de ressaltar o facto de a pertença ter sido assinalada pela utilização de nomes quer do lado paterno, quer do materno. ${ }^{17}$

Consoante a natureza e a intensidade da penetração germânica em cada região, houve variações no grau e rapidez da substituição de nomes latinos por nomes germânicos durante os primeiros séculos da Idade Média. Posteriormente, a partir do século $\mathrm{X}$, sempre com variações regionais, deu-se a substituição progressiva mas gradual de nomes germânicos por nomes cristãos. Em França, já mais de metade da população tinha nomes cristãos em meados do século XIII, enquanto que em Inglaterra a proporção rondava os 30\%. ${ }^{18}$

16 Assim, no caso de Publius Cornelius Scipio Nasica Corculum, que ocupou o cargo de pontifex maximus em 150 a.C., o seu nome próprio era Publius, Corculum era uma alcunha pessoal, e os restantes nomes indicam que ele pertencia ao ramo Nasica do segmento Scipio da gens Cornelia.

17 Para uma discussão do sistema germânico e da sua relação com o sistema de parentesco, baseada nos casos franco e anglo-saxónico, cfr. Wilson (1998: 70-85).

18 Wilson (1998: 88-90). 
Simultaneamente, começou a tornar-se mais frequente a utilização de dois nomes. Em documentos do Languedoc no século X, apenas 3\% das pessoas referidas tinha dois nomes, mas nos séculos XI e XII a proporção subiu para $36 \%$ e $72 \%$, respectivamente. Em 1300, a maioria dos contribuintes em Paris já usava dois nomes.

Esses nomes que se acrescentavam ao nome próprio eram de vários tipos. Podiam derivar: a) de alcunhas pessoais; b) de nomes próprios, às vezes com um prefixo ou sufixo a significar "filho de..."; c) de topónimos; ou d) de ocupações ou cargos. ${ }^{19}$ Serviam, em parte, para distinguir entre homónimos, mas também - no caso dos que derivavam de nomes próprios - para situar o indivíduo no interior da linhagem ou grupo familiar. Inicialmente, pelo menos, podiam ser considerados como um complemento, de natureza tendenciamente pessoal e intransmissível, ao nome próprio. Só mais tarde alguns começaram a funcionar como nomes de família, transmissíveis de geração em geração. Em Inglaterra e no Norte de França, foi apenas no século XV que os segundos nomes passaram a ser, em geral, nomes de família.

No célebre catasto mandado fazer pelas autoridades florentinas em 1427, a proporção dos contribuintes registados com nomes de família transmissíveis era de 9,4\% nas zonas rurais, 20,5\% nas cidades, e 36,7\% em Florença. ${ }^{20}$ Nos outros casos, ao nome próprio juntava-se, em geral, apenas a indicação do nome do pai. Estes números servem para ilustrar uma das hipóteses mais consistentes acerca da génese dos nomes de família. Comentando estudos sobre Bolonha e Paris no século XIII, Marc Bloch reconhecia que a tendência para a hereditariedade dos nomes de família se devia à influência de um "factor social", sob a forma de uma acção vinda do meio exterior à família: "relações, cada vez mais frequentes nas comunidades urbanas, do indivíduo com os seus concidadãos e com as autoridades; consequente necessidade de classificá-lo, para o distinguir dos seus numerosos homónimos, num subgrupo que será a família [...]." Mas, ao mesmo tempo, Bloch perguntava: "para explicar o nascimento dos nomes de família, não seria antes de olhar para a história interna da família em si?" 21 . Segundo Herlihy e Klapisch, o processo terá com efeito tido a sua origem na afirmação da linhagem agnática, que se terá sobreposto às estruturas bilaterais germânicas e traduzido na exigência de transmissão de um património material e simbólico a sucessivas gerações masculinas. ${ }^{22}$

Independentemente do peso respectivo destes dois factores, o externo e o interno, uma influência decisiva sobre os processos de nomeação em boa parte da Europa deveu-se ao movimento da Contra-Reforma católica e, mais

20 Herlihy e Klapisch (1978: 539). No bairro rico de Santa Croce, a percentagem era de 54\%.

21 Bloch (1932: 69).

22 Herlihy e Klapisch (1978: 543-4). 
especificamente, ao Concílio de Trento (1545-1563). Na sua tentativa de regulamentar o sacramento do matrimónio, e em particular a proibição do casamento entre parentes espirituais, os delegados reunidos em Trento estipularam que cada pároco deveria manter um livro de registo de baptismos, no qual registasse o nome dos padrinhos, e um livro de registo de matrimónios, no qual ficassem registados os nomes dos noivos e das testemunhas. ${ }^{23}$ Estas disposições, baseadas em propostas dos bispos reformadores da Península Ibérica e em algumas práticas já instituídas em Portugal e Espanha, foram completadas e formalizadas no Rituale Romanum de 1614, que estabeleceu para toda a Europa católica a forma precisa de registo de baptismos, casamentos e óbitos, bem como o modo como os párocos deveriam proceder ao arrolamento da população, agrupada em famílias, nos libri status animarum..$^{24}$ Nos registos de baptismo, a criança deveria ser registada com o seu nome, os pais com os nomes, o lugar de nascimento e a família, e os padrinhos com os nomes e os nomes dos respectivos pais. Nos de casamento, os noivos ficariam registados com os nomes e os nomes dos pais; e, no liber status animarum, os paroquianos deviam ser agrupados por famílias, com a indicação do nome, do nome de família (cognomen) e da idade. ${ }^{25} \mathrm{~A}$ instituição, pela Igreja, de um registo nominativo de todos os seus paroquianos, tendo em vista a sua fiscalização e identificação genealógica, acabou por dar a todos os nomes um carácter público e contribuiu para a padronização das práticas de nomeação.

$\mathrm{Na}$ maior parte dos países europeus, o sistema de nomeação em uso até aos nossos dias, em que um nome próprio, resultante de uma escolha individual ou familiar, é acompanhado por um nome de família hereditário na linha paterna ${ }^{26}$ ter-se-á cristalizado nos séculos XVI e XVII. ${ }^{27}$ Não será demasiado forçado argumentar que a consolidação deste modelo se deveu em grande parte

23 Il Sacro Concilio di Trento [...] (1785: Sess. XXIV, cap. I e II, 278-282).

24 Os libri status animarum, ou livros do estado das almas, correspondem aos róis de confessados portugueses, instituídos pela primeira vez no Sínodo de Braga de 1477. Destinavam-se a permitir a averiguação, pelo bispo, do cumprimento em cada paróquia da obrigação da confissão e comunhão anual, por altura da Páscoa.

25 Rituale Romanum [...] (1627: 362, 364-5, 367). Excepto no caso dos libri status animarum, em que se faz referência explícita ao cognomen, o texto refere apenas que o padre deverá escrever o "nome" - indicado pela abreviatura "N" - da criança baptizada, dos noivos, dos pais e dos padrinhos.

26 Cfr. Burguière (1984), que sublinha os mecanismos (p. ex. a escolha dos padrinhos, cujo nome próprio era muitas vezes dado à criança baptizada) através dos quais determinados nomes próprios eram transmitidos de uma geração a outra no interior do grupo familiar. Cfr., ainda, os restantes estudos reunidos em Dupâquier, Bideau e Ducreux (1984). Sublinhe-se, ainda, que a escolha dos padrinhos de entre os parentes quer do lado da mãe, quer do lado do pai, implicava - ao invés do nome de família, que era patrilinear - um stock bilateral de nomes próprios, cuja transmissão de geração em geração traduzia a dinâmica das alianças matrimoniais.

27 Em algumas zonas mais periféricas o processo só ficou concluído no século XIX. Para uma síntese, baseada nos casos melhor estudados da França e Inglaterra, cfr. Wilson (1998: 242-262). Cfr., ainda, sobre o caso francês, Collomp (1980); Zonabend (1977, 1980, 1984); Burguière (1980, 1984); Klapisch-Zuber (1984); e Bozon (1987). 
à tentativa, por parte da Igreja Católica ${ }^{28}$ de estender, através de registos escritos, a sua fiscalização a todas as paróquias, definindo, de acordo com regras uniformes, a identidade nominativa e o enquadramento familiar de todos os membros da população. ${ }^{29}$

V

Não dispomos, infelizmente, de trabalhos que permitam uma avaliação da especificidade das práticas de nomeação portuguesas no contexto europeu. ${ }^{30}$ Mesmo o estudo monumental de Leite de Vasconcellos (1928), já referido, é essencialmente filológico e, apesar de conter uma quantidade impressionante de informação acerca da origem e cronologia dos nomes portugueses e dos contextos da sua utilização, não permite uma análise quantitativa ou comparativa mais aprofundada. Apesar disso, a sua tipologia dos nomes e da sua evolução cronológica permite delinear os contornos de um modelo de nomeação.

Durante o período medieval teria inicialmente vigorado, para a maioria da população, um sistema de nome único. Muitos dos nomes utilizados (Gonçalo, Rodrigo, Afonso, Elvira, etc.) eram de origem germânica, mas alguns nomes de santos (António, João, Pedro, Dinis, Estevão, Catarina, entre outros) também eram utilizados. Com o tempo - a cronologia não é precisa - tornaram-se mais frequentes os casos de utilização de um segundo nome. ${ }^{31}$ Este podia ser um segundo nome próprio (p. ex. de carácter religioso), mas frequentemente era um patronímico no sentido rigoroso do termo, ou seja, um sobrenome derivado do nome próprio do pai ${ }^{32}$ (por exemplo, João Pires, filho de Pero Afonso).

28 Nos países protestantes o processo foi menos centralizado, mas os seus efeitos foram análogos.

29 Cfr. Carvalho e Brambilla (2006).

30 Devem, no entanto, ser referidos alguns estudos realizados no âmbito da demografia histórica sobre problemas de identificação nominativa (Marcílio 1974; Amorim 1983; Feijó 1987). Tomando como ponto de partida as dificuldades de utilização, em Portugal e no Brasil, do método de reconstituição de famílias concebido pelo demógrafo francês Louis Henry, sublinham as diferenças em relação ao modelo francês (apelidos múltiplos, variabilidade dos nomes ao longo da vida do indivíduo, transmissão nem sempre patrilinear dos apelidos) que dificultam a aplicação do método original.

31 Leite de Vasconcellos utiliza o termo sobrenome para designar: a) o segundo nome próprio, no caso de nomes próprios compostos (p. ex. Luís Manuel); b) um segundo nome próprio de carácter religioso (p. ex. Maria de São José); c) um patronímico no sentido estrito, derivado da forma genitiva de um nome próprio (p. ex. Pires, Vasques, Martins); e d) um nome próprio, sem vestígio da declinação latina, utilizado como patronímico (p. ex. João Afonso [filho de Afonso xxxx]). Utiliza, também, os termos apelido (para nomes hereditários) e alcunha (para designações pessoais, não hereditárias: p. ex. Grande, Velho, etc. ). Parece-me preferível englobar a) e b) na categoria de nomes próprios, e as categorias c) e d), juntamente com os apelidos e as alcunhas, numa categoria mais ampla de sobrenomes.

32 Alguns autores, particularmente em França, atribuem ao termo patronímico um sentido mais amplo, correspondente a qualquer nome, incluindo o(s) apelido(s), transmitido na linha paterna. Como veremos, o desenvolvimento do apelido em Portugal acompanhou o declínio dos patronímicos em sentido restrito, pelo que convém distinguir entre os dois termos. 
Ao patronímico em sentido estrito, que não se transmitia de pai para filho, mas que podia em certos casos transmitir-se de avô para neto, poderia vir a juntar-se um apelido, que normalmente designava um grupo de parentesco mais amplo (que poderia corresponder, por exemplo, a um topónimo, indicando o lugar de origem ou a localização da casa ou propriedades), e que se tornou hereditário. Ao patronímico e/ou ao apelido poderia, também, juntar-se uma alcunha de carácter pessoal. Temos, assim, para além do nome próprio, que podia ser simples ou composto, três tipos de sobrenome: o patronímico, o apelido e a alcunha.

Os nomes próprios poderiam, no caso de serem nomes transmitidos no âmbito do grupo de parentesco, servir para situar o indivíduo no interior do grupo, relacionando-o com outros parentes. Apesar de Leite de Vasconcellos lhes dedicar um curto capítulo do seu livro (1928: 82-94), os critérios de escolha do nome próprio em Portugal continuam em grande parte por esclarecer. Este autor fala de escolhas de carácter religioso (o nome do santo do dia do nascimento ou do baptismo da criança, ou de algum santo de devoção particular dos pais) e escolhas de carácter familiar ou de amizade (em que se homenageia algum parente ou amigo, ou o padrinho, dando o seu nome à criança). Mas nada diz acerca dos critérios de escolha. Em muitas regiões europeias, havia o costume de dar aos filhos, de acordo com a ordem de nascimento, o nome de determinados parentes. Assim, ao primogénito dar-se-ia, por exemplo, o nome do avô paterno; ao segundo, o do avô materno; ao terceiro, o do tio-avô (ou do tio) mais velho; e assim por diante. Os nomes das filhas também eram escolhidos de acordo com uma sequência pré-estabelecida de parentes. E apenas depois de cumprida esta obrigação familiar poderia, nas famílias mais numerosas, haver lugar a uma escolha mais pessoal por parte dos pais. ${ }^{33}$ Segundo vários autores franceses (cfr. por todos Burguière 1984), era este também o sistema seguido em boa parte da França rural durante a Época Moderna. Mas uma vez que, tradicionalmente, a escolha do nome competia aos padrinhos (que muitas vezes davam o seu próprio nome à criança), era vulgar escolherem-se como padrinhos aqueles parentes cujo nome se pretendia dar à criança ou, no caso de estes já não estarem vivos, uma outra pessoa com o mesmo nome. É provável que algo de semelhante tenha sido o costume em Portugal durante a Época Moderna, fazendo do nome próprio um elo simbólico de ligação entre a criança e determinados membros de sua parentela. ${ }^{34}$

33 A sequência aqui descrita corresponde à que era tradicionalmente seguida em Cisternino (Itália), onde fiz trabalho de campo em 1968-70, mas este é apenas um exemplo entre muitos referidos, em relação ao século XX, pela literatura etnográfica.

34 Cfr. Silva (1989). Para o confirmar, seria preciso reconstituir, em relação a populações suficientemente numerosas e representativas, o contexto imediato dos actos de baptismo: o nome da criança, os nomes dos padrinhos, as eventuais relações de parentesco destes com a família, e os nomes dos avós e outros parentes que poderiam ser escolhidos para transmitirem o seu nome à criança. [continua] 
O patronímico, pela sua própria natureza, serve não apenas para identificar como também para relacionar e para situar o indivíduo no interior do grupo de descendência. Em contrapartida, o apelido serve para identificar e designar, distinguindo-o dos restantes, o grupo no interior do qual o indivíduo se encontra englobado. Retomando as considerações já referidas de Marc Bloch (1932), podemos dizer que o apelido traduz as relações entre a família e o exterior (as autoridades, os restantes grupos de descendência), enquanto que o patronímico, tal como, no sistema descrito acima, o nome próprio, traduz a estrutura e as relações internas desse mesmo grupo. Isto não impede, contudo, que um patronímico se possa tornar hereditário, sendo transmitido de pai para filho como sobrenome e sendo, dessa forma, assimilado ao apelido.

A alcunha, por sua vez, é por natureza estritamente pessoal. Mas justamente porque serve para designar e identificar o indivíduo através de algum atributo pessoal, é susceptível de ser utilizado também por algum parente - em geral um filho - para sublinhar a sua relação com o portador original, e poderá, eventualmente, ser transmitido em seguida aos filhos deste, tornando-se, tal como o apelido, um marcador de identidade hereditário.

Segundo Leite de Vasconcellos, foi efectivamente isso que se passou, com a progressiva assimilação de patronímicos e de alcunhas aos apelidos hereditários. Esta transformação terá sido, em parte, consequência da crescente interacção entre a família e o exterior, mas poderá também, como no caso da Toscana no século XV, ter sido o reflexo de transformações na própria estrutura da família, com uma acentuação do seu carácter linhagístico. ${ }^{35}$ Independentemente das suas causas, foi este processo de transformação progressiva de patronímicos e alcunhas em apelidos que deu origem ao leque variado de apelidos utilizados pelos portugueses durante a Época Moderna. ${ }^{36}$ Por outro lado, o facto de os patronímicos ou desaparecerem ou se transformarem em apelidos hereditários poderá ter contribuído para o reforço do papel dos nomes próprios como marcadores simbólicos de relações no interior dos grupos de parentesco.

Apesar de laboriosa, esta investigação seria de execução relativamente simples a partir de registos paroquiais, e em particular dos relativamente numerosos estudos já efectuados de reconstituição de famílias. 35 Será, talvez, de se interpretar neste sentido o disposto nas Ordenações Manuelinas (liv. II, tit. 37 , n. ${ }^{\circ}$ 13), que visavam impedir a utilização de apelidos de fidalgos por parte de quem a eles não tivesse direito. Os cristãos-novos não estavam abrangidos por estas disposições e estavam autorizados a assumir livremente qualquer apelido, transmitindo-o aos seus filhos.

36 Ao contrário do que se terá passado em países como França, Itália ou Inglaterra, os apelidos - independentemente de sua origem - não eram sempre transmitidos de pai para filho, e a adopção em certas camadas sociais de apelidos múltiplos - também relativamente raros nesses países - favoreceu a sua transmissão bilateral e reforçou o seu carácter optativo. Determinado indivíduo poderia, assim, ter um ou mais nomes próprios, normalmente atribuídos no baptismo, e um ou mais apelidos, escolhidos de entre um conjunto mais amplo, e bilateral, de apelidos familiares. 
VI

O Rol de Confessados de Moncarapacho de 1545 regista os sobrenomes (patronímicos, apelidos e alcunhas) da população adulta residente em cada fogo, e permite ilustrar a tipologia estabelecida por Leite de Vasconcellos. Todos os adultos são referidos pelo nome próprio e por um ou mais sobrenomes. Quando o sobrenome é único, assume em geral a forma de um patronímico ou nome próprio, ${ }^{37}$ mas em alguns casos esse primeiro sobrenome é acompanhado por um apelido ou por uma alcunha. Como se poderá depreender do quadro 13, que regista todos os casos de sobrenomes compostos, os apelidos estão quase sempre ${ }^{38}$ associados a um nome próprio (utilizado como sobrenome) ou a um patronímico derivado de nome próprio. Em alguns casos, tratar-se-á de um verdadeiro patronímico, não transmitido como sobrenome de pai para filho. Mas, em outros, trata-se de um sobrenome hereditário, de um nome próprio a funcionar como apelido. Em todos eles, no entanto, o facto de haver pouca variedade nos nomes próprios leva ao risco de homonímia e à necessidade de uma identificação suplementar. Há, na lista, 16 indivíduos cujo primeiro sobrenome é Afonso. Destes, cinco chamavam-se João, quatro Gaspar e três Martim. Um segundo sobrenome servia, entre outras coisas, para os distinguir uns dos outros.

Alguns dos apelidos aqui apresentados, contudo, parecem ter outra natureza. Há nove indivíduos com o apelido Coruche. Destes, três são Vasques Coruche, dois Afonso Coruche e dois Dias Coruche. ${ }^{39}$ Não é possível, com base nesta documentação, saber se havia entre eles uma relação de parentesco, mas a existência de algum tipo de relação parece muito provável. Neste sentido, a generalização dos apelidos, em Portugal, poderá estar relacionada com alterações na maneira como a família e o grupo de parentesco - ou, em algumas regiões, a casa - funcionavam como unidades sociais intermediárias entre o indivíduo e a sociedade mais ampla.

A documentação aqui analisada não permite mais do que entrever a natureza destes processos de transformação. Mas em relação a um conjunto restrito de famílias, torna-se possível uma análise mais fina.

A reconstituição filológica de Leite de Vasconcellos, como se disse, permite estabelecer as grandes linhas do processo de transformação da antroponímia portuguesa entre a Idade Média e a Época Moderna, mas não fornece mais do que algumas pistas ténues para a reconstituição das práticas de nomeação que

37 Devido à natureza da fonte e à sua falta de profundidade genealógica não é possível, na maioria dos casos, saber se um nome próprio utilizado como sobrenome é um patronímico ou um apelido hereditário, pelo que esta categoria de sobrenomes não será analisada aqui.

38 A única excepção é o apelido Ramos, aqui completado pela alcunha "o Velho".

39 Havia ainda três indivíduos com o apelido Montes, dois Cansado, dois d'Estoi, dois Gago, dois Dourado, dois Barrancos. 
Quadro 13

Sobrenomes compostos: patronímicos, apelidos e alcunhas Moncarapacho, 1545

Afonso Bala
Afonso Barrancos
Afonso Camacho
Afonso Coruche (2)
Afonso Ereno
Afonso de Freitas
Afonso Gago
Afonso Galego
Afonso Grande
Afonso da Hortinha
Afonso Montes
Afonso Moreno
Afonso Nabo
Afonso Peral
Afonso Pilarta
Afonso Pires
Afonso da Quintã
Afonso Velho
Álvares Gato
Anes Gago
Dias do Campo
Dias Cansado
Dias Carvalho

Dias Coruche
Dias d'Estoi
Dias Repancho
Dias o Velho
Eanes Coruche
Eanes Vila
Eanes o Velho
Esteves da Rosa
Fernandes Castelhano
Fernandes Farelo
Fernandes de Fora
Fernandes Preta
Francisco Ingrês
Gonçalves Dourado
Gonçalves Rasca
Luís d'Areia
Luís Taborda (2)
Luís Vermelho
Luís Viseu
Lourenço Coruche
Lourenço Ermitão
Lourenço de Mendonça
Martins Barrancos

Martins de Bell Romão

Martins de Brás

Martins Cansado

Martins o Moço

Martins Montes (2)

Martins Mostrão

Martins Vilão

Pires Sobrinho

Ramos o Velho

Rodrigues Bilbao

Rodrigues d'Estoi

Rodrigues Testa

Rodrigues Tornes

Sanches a Velha

Vasques da Corte

Vasques Coruche (3)

Vasques Dourado

Vasques de Faram

Vasques Geraldo

Vasques Homem

Vasques o Moço

Vaz o Velho

Vicente Carneira

Fonte: ver nota 9. Foram aqui incluídas todas as instâncias de combinação de patronímico e apelido.

lhe estavam subjacentes. O Rol de Confessados de Moncarapacho de 1545 é um recenseamento, para fins pastorais, da população da freguesia em idade de confessar-se, agrupada por famílias. Encontram-se, assim, recenseados, juntamente com os pais, todos os filhos com mais de 7-8 anos. Os mais novos, tal como os criados e a maioria dos escravos, estão registados apenas com o nome próprio, mas em relação aos filhos mais velhos também foram registados os respectivos sobrenomes. O documento permite, assim, nestes casos (72 fogos), uma análise conjunta dos nomes de pais e filhos, abrindo espaço a uma primeira aproximação à transmissão dos nomes no interior da família e, indirectamente, à natureza da relação entre patronímicos e apelidos. 
O quadro 14 reproduz a informação pertinente à transmissão de nomes nos 72 fogos de Moncarapacho em que uma análise intergeracional é possível, e mostra a grande variedade de situações e formas de transmissão, entre pais e filhos, de patronímicos e apelidos.

Em 12 fogos (17\%) temos a indicação da persistência de mecanismos de nomeação patronímica. Na grande maioria dos casos (10), a transmissão é de pai para filho. Assim, o filho de Vasco Eanes chama-se Gabriel Vasques; o filho de Gaspar Pires chama-se Pêro; e o de Tomé Pires chama-se Pêro Martins. ${ }^{40}$ Mas há dois casos em que uma filha adquire o patronímico paterno - Briolanja Nunes, que é filha de Nuno Vasques, e Maria Gonçalves, filha de Gonçalo Eanes -, e ainda outro, mais confuso, em que, segundo parece, o sobrenome da mãe, Joana Pires, de origem patronímica, é transmitido como apelido a um dos filhos (João Pires) mas determina, segundo uma lógica mais antiga de transmissão patronímica, a escolha do nome próprio Pêro para o filho mais novo.

Em 12 fogos temos a transmissão como apelido, de pai/mãe para filho/filha, de um sobrenome de origem patronímica (p. ex. Martins, Afonso, Vasques, Rodrigues). Há seis casos em que a transmissão é de pai para filho, sete em que é de pai para filha, e um (já mencionado) de mãe para filho. Em onze desses fogos, o pai possuía um sobrenome duplo (p. ex. Francisco Roiz Bilbao) que, no entanto, não é registado como tendo sido transmitido à geração seguinte. Será de admitir que o segundo sobrenome estaria subentendido pelo facto de os filhos estarem registados juntamente com os pais ou, alternativamente, que este tipo de apelido só se adquiria quando o filho se casava e passava a residir num fogo à parte.

Em seis fogos temos a transmissão de pai para filho (5) ou de pai para filha (1) de um sobrenome não patronímico. Em quatro desses casos, o pai possuía um sobrenome de origem patronímica que não foi transmitido: Joane Freitas, filho de Gaspar Afonso de Freitas; Diogo de Mendonça, filho de Domingos Lourenço de Mendonça.

Em cinco fogos temos a transmissão de um sobrenome de origem patronímica de mãe para filha, sendo que num desses casos o filho recebeu o apelido do pai, João Revez.

Em 14 fogos, por fim, encontramos uma situação em que um ou mais dos filhos se encontra registado com um sobrenome não partilhado com qualquer dos pais.

No conjunto, e excluídos os casos de transmissão patronímica referidos no início, temos 35 casos de filhos e 54 casos de filhas cujo sobrenome se encontra registado. Em relação aos filhos, 74\% receberam-no do pai, e nos restantes casos o sobrenome não era de qualquer dos pais. Em relação às filhas, $11 \%$ receberam o sobrenome da mãe, 39\% do pai e 50\% de nenhum dos dois. 
Quadro 14

Transmissão de nomes entre gerações (patronímicos e apelidos)

Moncarapacho, 1545

\begin{tabular}{|c|c|c|c|c|}
\hline & MARIDO & MULHER & FILHO(S) & FILHA(S) \\
\hline 1 . & Afonso Fernandes & - & Nuno Fernandes & - \\
\hline 2 . & Afonso Lourenço & - & - & Domingas Lourenço \\
\hline 3. & Afonso Marques & - & $\begin{array}{l}\text { Miguel Marques } \\
\text { Lourenço Marques }\end{array}$ & - \\
\hline 4. & Álvaro Afonso & - & - & Isabel Gonçalves \\
\hline 5 . & Álvaro Esteves & - & - & Catarina Dias \\
\hline 6. & Álvaro Fernandes & - & $\begin{array}{l}\text { Domingos Fernandes } \\
\text { João Fernandes }\end{array}$ & Leonor Fernandes \\
\hline 7. & António Afonso & - & $\begin{array}{l}\text { António Afonso } \\
\text { João Afonso }\end{array}$ & Maria Afonso \\
\hline 8 . & António Fernandes & Maria Vasques & - & Isabel Vasques \\
\hline 9. & António Machado & - & Afonso Montes & $\begin{array}{l}\text { Antónia Montes } \\
\text { Maria Beiça }\end{array}$ \\
\hline 10. & António Martins & - & Vicente Martins & Catarina Martins \\
\hline 11. & Baltasar Luís & - & João Luís & - \\
\hline 12. & Baltasar Martins Vilão & - & - & Elvira Lopes \\
\hline 13. & - & Bárbara Afonso & (neto) Manuel Afonso & $\begin{array}{l}\text { Susana Afonso } \\
\text { Maria Afonso }\end{array}$ \\
\hline 14. & Bartolomeu Álvares & - & - & Maria Álvares \\
\hline 15. & Bartolomeu Dias & - & - & $\begin{array}{l}\text { Beatriz Dias } \\
\text { Bárbara Domingues }\end{array}$ \\
\hline 16. & $\begin{array}{l}\text { Bartolomeu Dias } \\
\text { do Campo }\end{array}$ & - & - & Catarina Dias \\
\hline 17. & $\begin{array}{l}\text { Bartolomeu Vasques } \\
\text { Coruche }\end{array}$ & - & $\begin{array}{l}\text { Diogo Vasques } \\
\text { António Vasques }\end{array}$ & Catarina Vasques \\
\hline 18. & Bastião Afonso Pires & - & $\begin{array}{l}\text { Manuel Pires } \\
\text { Pêro }\end{array}$ & Filipa Martins \\
\hline 19. & Bastião da Costa & - & - & Beatriz Martins \\
\hline 20. & Bastião Fernandes & - & João Fernandes & - \\
\hline 21. & Bastião Mendes & - & - & Isabel Mendes \\
\hline 22 . & Belchior de Veigas & - & - & Leonor de Oliveira \\
\hline 23. & Brás Eanes & - & Álvaro Fernandes & Domingas Brás \\
\hline 24 . & Brás Fernandes & - & Domingos Fernandes & Catarina Fernandes \\
\hline 25 . & $\begin{array}{l}\text { Cristóvão Martins } \\
\text { Barrancos }\end{array}$ & - & Afonso Gago & Maria Vasques \\
\hline 26. & Diogo Afonso & Apolónia da Rosa & - & Cecília da Rosa \\
\hline
\end{tabular}




\begin{tabular}{|c|c|c|c|c|}
\hline & MARIDO & MULHER & FILHO(S) & FILHA(S) \\
\hline 27. & Diogo Afonso Ereno & - & Lourenço Dias & - \\
\hline 28. & Diogo da Costa & - & Brás da Costa & Catarina Arrais \\
\hline 29. & Diogo Martins & Bárbara Afonso & - & Catarina Afonso \\
\hline 30. & Diogo Martins & - & Baltasar Martins & - \\
\hline 31. & $\begin{array}{l}\text { Diogo Martins } \\
\text { de Bell Romão }\end{array}$ & - & - & $\begin{array}{l}\text { Juliana Dias } \\
\text { Bárbara Roiz }\end{array}$ \\
\hline 32. & Domingos Gonçalves & - & - & Catarina Roiz \\
\hline 33. & $\begin{array}{l}\text { Domingos Lourenço } \\
\text { de Mendonça }\end{array}$ & - & Diogo de Mendonça & - \\
\hline 34. & $\begin{array}{l}\text { Domingos Martins } \\
\text { Montes }\end{array}$ & - & - & Catarina de Brito \\
\hline 35. & Diogo Pires & - & Domingos Gonçalves & - \\
\hline 36. & Estevão Martins & - & $\begin{array}{l}\text { André Gonçalves } \\
\text { Vicente Gago }\end{array}$ & Catarina Esteves \\
\hline 37. & Fernando Esteves & - & Estevão Afonso & - \\
\hline 38. & Fernão Godinho & - & - & Mor Eanes \\
\hline 39. & Fernão Vaz o Velho & - & João Gonçalves & - \\
\hline 40. & $\begin{array}{l}\text { Francisco Martins } \\
\text { Cansado }\end{array}$ & - & Domingos Martins & Beatriz Martins \\
\hline 41. & Francisco Roiz Bilbao & - & Pêro Roiz & - \\
\hline 42. & $\begin{array}{l}\text { Gaspar Afonso } \\
\text { de Freitas }\end{array}$ & - & Joane Freitas & - \\
\hline 43. & Gaspar Gonçalves & - & - & Graça Dias \\
\hline 44. & Gaspar Luís Taborda & - & - & $\begin{array}{l}\text { Catarina Gonçalves } \\
\text { Leonor Martins }\end{array}$ \\
\hline 45. & Gaspar Pires & - & Pêro & - \\
\hline 46. & Gonçalo Eanes & - & - & Maria Gonçalves \\
\hline 47. & Gonçalo Lourenço & - & - & Inês d'Oliva \\
\hline 48. & Gonçalo Viegas & - & Fernão Viegas & - \\
\hline 49. & - & Joana Pires & $\begin{array}{l}\text { João Pires } \\
\text { Pêro Álvares }\end{array}$ & - \\
\hline 50. & João Afonso Camacho & - & - & Maria Camacha \\
\hline 51. & João Afonso Moreno & - & - & Constança Afonso \\
\hline 52. & João André & - & - & Bárbara Gonçalves \\
\hline 53. & João Dias Repancho & - & Jorge Dias & $\begin{array}{l}\text { Isabel Esteves } \\
\text { Inês Esteves }\end{array}$ \\
\hline 54. & João Esteves & - & Domingos Afonso & - \\
\hline 55. & João Esteves da Rosa & - & - & Maria Esteves \\
\hline
\end{tabular}




\begin{tabular}{|llll}
\hline MARIDO & MULHER & FILHO(S) & FILHA(S) \\
\hline 56. João Martins o Velho & - & Rodrigo Afonso & Isabel Roiz \\
\hline 57. João Revez & Inês Roiz & João Revez & Leonor Roiz \\
\hline 58. João Roiz Testa & - & - & Mor Roiz \\
\hline 59. João Vasques Geraldo & - & - & Bárbara Vasques \\
\hline 60. Lourenço Martins & - & André Domingues & Margarida Álvares \\
\hline 61. Lourenço Martins & - & & Catarina André \\
\hline Montes & - & - & Catarina Martins \\
\hline 62. Martim Afonso Grande & - & Francisco Martins & Beatriz Afonso \\
\hline 63. Martim Esteves & - & João Esteves & Catarina Esteves \\
\hline 64. Martim Luís & - & - & Maria Afonso \\
\hline 65. Nuno Gonçalves & - & Francisco Nunes & - \\
\hline 66. Nuno Vasques & - & - & Briolanja Nunes \\
\hline 67. Pêro Martins & - & Domingos Martins & - \\
\hline 68. Rodrigo Eanes & - & Domingos Gonçalves & Constança Gonçalves \\
\hline 69. Tomé Pires & - & Pêro Martins & \\
\hline 70. Vasco Eanes & - & Manuel de Tomé Pires & - \\
\hline 71. Vicente Afonso & - & Gabriel Vasques & - \\
\hline 72. (ileg.) Gonçalves & - & Miguel Afonso & - \\
\hline
\end{tabular}

Em itálico as transmissões de apelidos; em negrito as transmissões patronímicas.

Fonte: ver nota 9. Foram aqui incluídos os 72 fogos em relação aos quais havia alguma informação acerca das transmissão entre gerações de nomes próprios e sobrenomes.

VII

Para além da grande variedade de situações e mecanismos que podem ser observados mesmo nesta amostra tão reduzida, torna-se evidente a multiplicidade de relações simbólicas que as práticas de nomeação estabelecem no interior da parentela. Bastaria que extrapolássemos uma geração para trás ou para diante, de modo a incluirmos um universo de parentesco - três gerações - que corresponde à experiência vivida da maioria da população, para podermos entrever a densa teia de relações simbólicas tecida pelas práticas de nomeação e transmissão de patronímicos e sobrenomes. ${ }^{41}$

41 Devemos aqui incluir também, evidentemente, as relações estabelecidas pela transmissão de nomes próprios no interior dos grupos de parentesco. 
No Algarve rural de meados do século XVI, não parece, contudo, possível - pelo menos, com base nesta única fonte - identificar algum modelo coerente em relação a essas práticas. A sua própria diversidade será, porventura, consequência de uma situação de transição, em que um modelo patronímico, complementado nalguns casos por apelidos e alcunhas, estava em vias de ser substituído por um modelo baseado na transmissão, entre uma geração e outra, de diferentes tipos de apelidos, muitos dos quais também de origem patronímica. Mas esta mesma diversidade poderá também ser indício de alguma especificidade nas práticas de nomeação em Portugal, talvez partilhada, pelo menos em parte, com as da Espanha, mas seguramente distintas das que predominavam além-Pirenéus.

\section{BIBLIOGRAFIA}

AMORIM, Norberta, 1983, "Identificação de pessoas em duas paróquias do Norte de Portugal (1580-1820)", Boletim de Trabalhos Históricos, XXXIV, Guimarães, pp. 214 -278 .

BLOCH, Marc, 1932, "Noms de personne et histoire sociale", Annales d'Histoire Economique et Sociale, 4, pp. 67-69.

BOZON, Michel, 1987, "Histoire et sociologie d'un bien symbolique, le prénom”, Population, XLII/1, pp. 83-98.

BURGUiÈRE, André, 1984, "Prénoms et parenté", em Dupâquier, Bideau e Ducreux, pp. 29-36.

—, 1980, "Un nom pour soi", L'Homme, XX/4, pp. 25-42.

CARVALHO, J.R., e E. Brambilla, 2006, "Religion and Citizenship from the Ancien Regime to the French Revolution”, em Steven G. Ellis, Guðmundur Hálfdanarson e Ann Katherine Isaacs (orgs.), Citizenship in Historical Perspective. Pisa, Edizioni Plus - Pisa University Press, pp. 35-60.

COLlOMP, Alain, 1980, "Le nom gardé", L'Homme, XX/4, pp. 43-61.

DUPÂQUIER, J., A. Bideau, e M.-E. Ducreux (orgs.), 1984, Le Prénom. Mode et Histoire. Paris, École des Hautes Études en Sciences Sociales.

FEIJÓ, Rui Graça, 1987, "Um exercício sobre nomes”, Boletín de la Asociación de Demografía Histórica, V/1, pp. 50-63.

HERLIHY, D., e C. Klapisch, 1978, Les Toscans et Leurs Familles. Paris, Fondation Nationale de Sciences Politiques/Ecole des Hautes Etudes en Sciences Sociales.

Il Sacro Concilio di Trento, con le notizie più precise riguardanti la sua intimazione a ciascuna delle sessioni, 1785. Veneza, Eredi Baglioni.

KLAPISCH-ZUBER, C., 1984, "Constitution et variations temporelles des stocks de prénoms”, em Dupâquier, Bideau e Ducreux, op. cit., pp. 37-47. 
MARCíliO, Maria Luíza, 1974, "Anthroponymie au Brésil”, em Louis Henry (dir.), Noms et Prénoms. Liège, Ordina.

Rituale Romanum Pauli Quinti iussu editum, 1627. Veneza, Nicola Messerino.

ROWLAND, Robert, 1999, "Être juif au Portugal au temps de l'Inquisition: nouveaux chrétiens, marranes, juifs”, Ethnologie Française, XXIX/2, pp. 191-203.

SANTOS, Maria Leonor Ferraz de Oliveira Silva, (2003), "A onomástica, o indivíduo e o grupo", Arquipélago - História, 2. a série, VII, pp. 229-242.

SILVA, Francisco Vaz da, 1989, "Aspectos do compadrio", em AAVV, Estudos de Homenagem a Ernesto Veiga de Oliveira, Lisboa, Instituto Nacional de Investigação Científica, pp. 861-898.

VASCONCEllos, J. Leite de, 1928, Antroponímia Portuguesa. Tratado comparativo da origem, significação, classificação e vida do conjunto dos nomes próprios, sobrenomes, e apelidos, usados por nós desde a Idade-Média até hoje, Lisboa, Imprensa Nacional.

WILSON, Stephen, 1998, The Means of Naming. A social and cultural history of personal naming in Western Europe, Londres, UCL Press.

WINCHESTER, Ian, 1973, "On referring to ordinary historical persons", em E. A. Wrigley (ed.), Identifying People in the Past, Londres, Arnold, pp. 17-40.

ZONABEND, Françoise, 1984, "Prénom et identité", em Dupâquier, Bideau e Ducreux, op. cit., pp. 23-28.

— 1980, "Le nom de personne", L'Homme, XX/4, pp. 7-23.

—, 1977, "Pourquoi nommer?”, em Claude Lévi-Strauss (org.), L'Identité. Paris, Presses Universitaires de France, pp. 257-279.

Naming practices in early modern Portugal: a preliminary approach - Robert Rowland - Departamento de Antropologia - ISCTE/CEAS/CRIA • robert.rowland@iscte.pt

This article is a first attempt at reconstructing naming practices in early modern Portugal. Different kinds of sources (Inquisition records and local census materials, both ecclesiastical and military) are used to trace the emergence, in the Sixteenth Century, of a model based on the combination of personal names and family names, transmissible from one generation to the next. This process is analyzed within a broader time-frame (from the Roman period), and appears to indicate the specificity of Iberian models within the European context.

KEYWORDS: name, family, lineage, Portugal, early modern period. 